\title{
Stopping breastfeeding to prevent vertical transmission of HTLV-1 in resource-poor settings: beneficial or harmful?
}

\author{
Carla van Tienen • Marianne Jakobsen • \\ Maarten Schim van der Loeff
}

Received: 6 September 2011 / Accepted: 31 December 2011 / Published online: 7 January 2012

(C) The Author(s) 2012. This article is published with open access at Springerlink.com

In a recent issue of this journal Mylonas et al. [1] reviewed human T-lymphotropic virus type 1 (HTLV-1) infection and its implications in gynecology and obstetrics. Although HTLV-1 is rare in many populations, it occurs worldwide and is associated with a substantial disease burden and a high risk of vertical transmission. The authors provide recommendations for prevention of sexual and vertical transmission of HTLV-1. One of the recommendations is the following: 'If stopping breastfeeding is not possible, for example due to socio-economical circumstances, shortterm breastfeeding for 3 to a maximum of 6 months should be advocated'. The recommendation in the review is based on two studies from Japan showing reductions of vertical transmission by limiting or avoiding breastfeeding. To our knowledge, no international guidelines exist (e.g. from the WHO or CDC) on breastfeeding and HTLV-1 prevention in resource-poor, developing countries. Therefore, it is important to carefully take into account the risks versus the benefits of advocating short-term breastfeeding in developing countries.

Various studies have shown that prolonged breastfeeding is associated with an increased risk of HTLV-1 transmission and avoiding breastfeeding can lead to a dramatic

\section{C. van Tienen $(\varangle)$}

Medical Microbiology and Infectious Diseases, Erasmus Medical Centre, 's-Gravendijkwal 230, Rotterdam, The Netherlands e-mail: c.vantienen@erasmusmc.nl

\section{Jakobsen}

Paediatric Department, Kolding Sygehus,

Skovvangen 2-4, 6000 Kolding, Denmark

M. Schim van der Loeff

Department of Infectious Diseases, Health Service of Amsterdam, Nieuwe Achtergracht 100, Amsterdam, The Netherlands reduction in transmission [2]. A high maternal proviral load in combination with waning antibodies in the child leads to an increased risk of HTLV-1 transmission, especially after 6-12 months after birth [3]. However, the key question is whether the benefits of avoiding HTLV-1 infection outweigh the risks of not breastfeeding. As the review points out, HTLV-1 causes adult T-cell leukemia (ATL) or tropical spastic paraparesis (TSP) in about $5 \%$ of infected individuals and is associated with a number of infections and inflammations. On the other hand, the risks of early weaning are substantial. The promotion of breastfeeding for 6-11 months has been estimated to be the most effective strategy to prevent child mortality in resourcelimited settings and the WHO recommends at least 6 months of exclusive breastfeeding [4]. Our work in Guinea-Bissau, one of the poorest countries in Sub Saharan Africa with a high prevalence of HTLV-1 (5\%) [5, 6], has shown that early weaning (before 12 months) is associated with increased mortality and increased risk of diarrheal diseases among children [7, 8]. For example, the mortality among weaned children was sixfold higher compared to breastfed children during the civil war in GuineaBissau in 1996-1997 [7].

In many Sub Saharan countries, vertical transmission of HIV is of major concern. In an editorial from 2010, Humphrey points out the increasing amount of data supporting the fact that in Sub Saharan Africa the risks of early weaning do not outweigh the risks of a possible HIV infection [9]. The 2010 UNAIDS guidelines advice at least 6 months of exclusive breastfeeding and advice to continue breastfeeding after this time if replacement feeding is not feasible, even when anti-retroviral (ARV) drugs are not available (if available, ARVs are recommended for mother and child to reduce the risk of transmission) [10]. Thus, for an infection that has much larger health implications 
than HTLV-1, breastfeeding longer than 6 months is recommended in certain settings where replacement feeding is not feasible.

HTLV-1 infected pregnant women from a poor socioeconomic background in a developed country merit extra attention and the advice about not breastfeeding should be tailored to the exact circumstances of the woman. However, it is very likely that these women will have access to good replacement feeding and therefore it seems rational to advise them similarly as women from higher socio-economic status, i.e., to refrain from breastfeeding altogether.

In conclusion, in resource-poor settings, like GuineaBissau, the immediate health risks of the advocated weaning at 3-6 months are likely to be bigger than the risks of HTLV-1 related morbidity and mortality. This is likely to vary by country and will strongly depend on the socio-economic circumstances and current breastfeeding practices in the country. The available data so far do not support early weaning to prevent vertical transmission of HTLV-1 in resource-limited settings.

Conflict of interest We declare that we have no conflict of interest.

Open Access This article is distributed under the terms of the Creative Commons Attribution Noncommercial License which permits any noncommercial use, distribution, and reproduction in any medium, provided the original author(s) and source are credited.

\section{References}

1. Mylonas I, Bruning A, Kainer F, Friese K (2010) HTLV infection and its implication in gynaecology and obstetrics. Arch Gynecol Obstet 282(5):493-501

2. Kashiwagi K, Furusyo N, Nakashima H et al (2004) A decrease in mother-to-child transmission of human T lymphotropic virus type I (HTLV-I) in Okinawa, Japan. Am J Trop Med Hyg 70(2):158-163

3. Hisada M, Maloney EM, Sawada T et al (2002) Virus markers associated with vertical transmission of human $\mathrm{T}$ lymphotropic virus type 1 in Jamaica. Clin Infect Dis 34(12):1551-1557

4. Kramer MS, Kakuma R (2002) Optimal duration of exclusive breastfeeding. Cochrane Database Syst Rev 1:CD003517

5. Jakobsen MS, Sodemann M, Molbak K, Alvarenga IJ, Nielsen J, Aaby P (2003) Termination of breastfeeding after 12 months of age due to a new pregnancy and other causes is associated with increased mortality in Guinea-Bissau. Int J Epidemiol 32(1):92-96

6. van Tienen C, Schim van der Loeff MF, Peterson I (2010) HTLV-1 in rural Guinea-Bissau: prevalence, incidence and a continued association with HIV between 1990 and 2007. Retrovirology 7(1):50

7. Jakobsen M, Sodemann M, Nylen G et al (2003) Breastfeeding status as a predictor of mortality among refugee children in an emergency situation in Guinea-Bissau. Trop Med Int Health 8(11):992-996

8. Molbak K, Gottschau A, Aaby P, Hojlyng N, Ingholt L, da Silva AP (1994) Prolonged breast feeding, diarrhoeal disease, and survival of children in Guinea-Bissau. BMJ 308(6941):1403-1406

9. Humphrey JH (2010) The risks of not breastfeeding. J Acquir Immune Defic Syndr 53(1):1-4

10. UNAIDS (2010) Guidelines on HIV and infant feeding 2010. http:// whqlibdoc.who.int/publications/2010/9789241599535_eng.pdf 